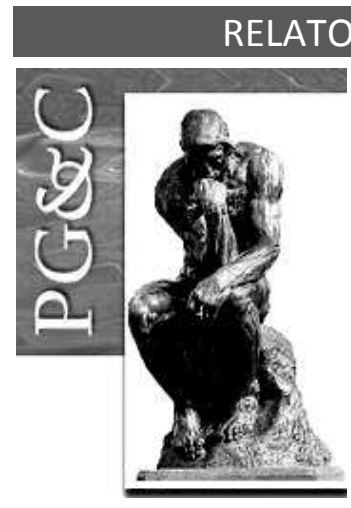

\title{
FACILITAR OU DIFICULTAR? CAMINHOS PARA A GESTÃO DO CONHECIMENTO
}

\author{
Marcilde Sabadin Telles \\ Mestre em Administração pela Universidade de Passo Fundo, Brasil. \\ Professora da Faculdade João Paulo II, Brasil. \\ E-mail: marcildesabadintelles@gmail.com \\ Anelise Rebelato Mozzato \\ Doutora em Administração pela Universidade do Vale do Rio dos Sinos, \\ Brasil. Professora da Universidade de Passo Fundo, Brasil. \\ E-mail: anerebe@upf.br
}

\begin{abstract}
Resumo
Este artigo objetiva evidenciar a interferência de barreiras e facilitadores da gestão do conhecimento e sua implicação no desempenho organizacional em três empresas industriais de médio porte em cidade ao norte do estado do Rio Grande do Sul. Ao realizar uma pesquisa multicasos de caráter qualitativo, exploratória e descritiva, os dados são coletados por meio de técnicas diversificadas (entrevista, observação não participante, análise documental), abrangendo dezessete gestores. Os dados coletados são triangulados e analisados por meio da análise de conteúdo. As sete dimensões da gestão do conhecimento trabalhadas por Terra (2007) são observadas no contexto empírico e identificadas barreiras e facilitadores que permitem sua execução. Os resultados da pesquisa empírica evidenciam que as práticas de gestão do conhecimento necessitam ser compreendidas e aplicadas de fato, as quais podem ser interdependentes entre si, promovendo desempenho organizacional, mesmo ao perpassar por barreiras relacionadas à gestão do conhecimento. Logo, conclui-se que há que se relacionar intimamente a gestão do conhecimento com a área de GP, principalmente nas macro estratégias da alta administração e nos sistemas de informação e comunicação, bem como na mensuração dos resultados, o que facilita, sobremaneira, a sua efetivação.
\end{abstract}

Palavras-chave: Gestão do Conhecimento. Dimensões da Gestão do conhecimento. Facilitadores. Barreiras.

\section{FACILITATE OR HINDER? PATHWAYS TO KNOWLEDGE MANAGEMENT}

\begin{abstract}
This paper aims to highlight the interference of knowledge management (KM) barriers and their implication in organizational performance in three medium-sized industrial companies in a city north of the state of Rio Grande do Sul. In conducting a qualitative, exploratory multi-site research and descriptive, the data were collected through a variety of techniques (interview, non-participant observation, documentary analysis), covering seventeen managers. After rectifying the collection instruments in the pilot project, the research was extended to the other industrial companies. The collected data were triangulated and analyzed through content analysis. The seven dimensions of GC worked by Terra (2007) were observed in the empirical context and identified barriers and facilitators that allow their execution. The results of the empirical research show that the practices to be understood and applied in fact, which may be interdependent, promoting organizational performance, even when crossing barriers related to KM. Therefore, it is concluded that the KM should be closely related to the resources human management, mainly in the macro-strategies of top management and in the information and communication systems, as well as in the measurement of results, which would greatly facilitate its effectiveness.
\end{abstract}

Keywords: Knowledge Management. Dimensions of Knowledge Management. Facilitators. Barriers.

Perspectivas em Gestão \& Conhecimento, João Pessoa, v. 10, n. 1, p. 39-53, jan./abr. 2020. DOI: http://dx.doi.org/10.21714/2236-417X2020v10n1p39

http://periodicos.ufpb.br/ojs2/index.php/pgc. ISSN: 2236-417X. Publicação sob Licença (cc) EY-NC-ND 


\section{INTRODUÇÃO}

A gestão do conhecimento (GC) tem permeado debates acadêmicos, sobretudo a partir do desenvolvimento da teoria da criação do conhecimento organizacional (NONAKA; TAKEUCHI, 1997). Nessa lógica, trabalhos são desenvolvidos na ótica do compartilhamento do conhecimento, inibidores, facilitadores, e práticas da GC utilizadas nas organizações (JOIA; OLIVEIRA, 2007; TEIXEIRA; OLIVEIRA, 2012; FERNANDES et al., 2015).

Outrossim, o presente artigo se propõe analisar as contribuições das sete dimensões da GC mencionadas por Terra (2007), justifica-se a pesquisa tendo em vista que a GC, por sua complexidade, torna-se relevante ao ponderar as sete dimensões propostas pelo autor, em pequenas práticas que podem ser colocadas em ação ou evitadas, por serem vistas como facilitadores ou barreiras, respectivamente. Facilitadores são os fatores que oportunizam, facilitam ou viabilizam a prática da GC. Por sua vez, barreiras são os fatores que a dificultam ou a atrapalham (SORDI et al., 2017). Portanto, facilitar é tornar algo possível de se realizar, ser exequível; dificultar é interpor barreiras, empecilhos, impedir ou atrapalhar. Assim, de forma prática, neste artigo são enfatizadas ações que podem facilitar ou dificultar as dimensões da GC proferidas por Terra (2007).

Nessa lógica, Terra $(2001 ; 2007)$ entende que se faz necessário o esforço para fazer com que o conhecimento de uma organização esteja disponível para as pessoas e organizações, aumentando tanto o desempenho humano como organizacional. Entretanto, como bem pontuam Burger et al. (2018), existem fatores críticos para a implementação da GC, dentre eles, salientam a necessidade de maior investimento na cultura e na estrutura organizacional.

Portanto, Terra (2001) já salientava a necessidade de mais pesquisas sobre GC, assim como mais recentemente tal necessidade ainda é apontada em vários estudos, a exemplo dos desenvolvidos por Bessi et al. (2017), Sordi et al. (2017) e Burger et al. (2018). Mais especificamente em relação a facilitares e barreiras na GC, tal necessidade de mais pesquisas é salientada por Fernandes et al. (2015), assim como por Sordi et al. (2017). E ainda, relacionando a GC com o desempenho organizacional, destacam-se os trabalhos de Centenaro, Bonemberger e Laimer (2016) e Ribeiro et al. (2017).

Diante do fato de haverem lacunas de pesquisa sobre o tema e, consequentemente a necessidade de mais pesquisas, sobretudo empíricas, este artigo tem como objetivo evidenciar a interferência de barreiras e facilitadores da GC e sua implicação no desempenho organizacional em três empresas industriais de médio porte em cidade ao norte do estado do Rio Grande do Sul.

O artigo está estruturado da seguinte maneira: após essa introdução, apresenta-se a abordagem teórica sobre o tema pesquisado. Na sequência, os procedimentos metodológicos são delineados e os resultados apresentados e discutidos. Por fim, expõem-se as conclusões com a apresentação de sugestões para estudos futuros.

\section{ABORDAGEM TEÓRICA}

A competição entre empresas, ainda mais nesse novo contexto do mercado, depende do conhecimento diferenciado. Por isso, a criação e o compartilhamento do conhecimento devem ser facilitados, dentro de uma atmosfera de renovação de ideias e compartilhamento mútuo entre os trabalhadores e a própria organização. Assim, fomentar um ambiente que, mesmo com limitadores para a prática de tais ações seja possível implementá-lo, torna-se preponderante. Essas práticas dependem muito das pessoas e principalmente, torna-se um desafio maior para as lideranças, pois o papel do líder na integração de equipes para um objetivo comum, sugere avanços quando as ideias são ouvidas e valorizadas. Nesse sentido Gonçalo (2005) infere que a liderança é um dos fatores facilitadores para a disseminação do

Perspectivas em Gestão \& Conhecimento, João Pessoa, v. 10, n. 1, p. 39-53, jan./abr. 2020. 
conhecimento, pois o compartilhamento resulta no respeito dentro da equipe e corrobora a motivação da transmissão do conhecimento.

Então, a liderança enquanto moderadora pode em muito facilitar para agregar mais competências e atuar com mais práticas e ferramentas que melhorem o acesso às informações e ao conhecimento para suas equipes de trabalho (BESSI et al., 2017), tornando-as mais competitivas. No atual ambiente de mercado, onde as empresas devem operar e difundir suas competências, a competitividade é estruturalmente mais complexa do que aquela apresentada aos que estavam acostumados a competir. É nesse contexto que a GC entra como importante para o melhor desempenho das organizações, como bem pontuam Gonçalo e Borges (2010), Fernandes et al. (2015), Centenaro, Bonemberger e Laimer (2016) e Ribeiro et al. (2017).

A evolução dos estudos acerca da GC, teve início em Wiig (1993), que em sua apresentação na segunda conferência anual da International Association of Knowledge Engineers, ocorrida em 1986, enfatizou pela primeira vez a GC associada ao desempenho organizacional. O mesmo autor em 2004, ao aprofundar suas pesquisas apresenta um modelo simplificado de funções sistêmicas e as ligações dentro de uma empresa comercial, e indica os quatro fatores principais: direcionadores, habilitadores, facilitadores e mecanismos. Assim, Wiig (2004), infere que há uma perspectiva no papel dos fatores ativos, que ao se interligarem possibilitam a visualização dos meios que facilitam as práticas da GC, permitindo maior desempenho da empresa. Nesse sentido Gonçalo e Borges (2010, p. 63) referem:

$\mathrm{Na}$ visão baseada em gestão de pessoas, a GC é percebida como um processo resultante de um conjunto de habilidades e competências humanas dinamicamente envolvidas com o conhecimento através das pessoas. Quando o conhecimento é entendido como processo, o investimento nas pessoas proporcionará melhores resultados para a organização.

O objetivo geral da GC é maximizar a eficácia e o retorno de seus ativos de conhecimento relacionado à organização, buscando a renovação permanente. Dessa forma, a GC é vista como importante para o desempenho organizacional, uma vez que os facilitadores que contribuem para que ela ocorra. Portanto, entende-se que quando a GC necessita ser estimulada e incentivada pelos líderes, com a aplicação de práticas de gestão envolvendo as pessoas, as quais são as únicas detentoras do conhecimento. Possuir práticas e ferramentas que facilitem o acesso as informações e ao conhecimento são necessárias (BESSI et al., 2017), pois vale o esforço para fazer com que o conhecimento de uma organização esteja disponível para aqueles que dele necessitem, quando, onde, e na forma como se faça necessário. Afinal, tais práticas e ferramentas tem como objetivo aumentar o desempenho humano e o desempenho organizacional (TERRA, 2001; FERNANDES et al., 2015; RIBEIRO et al., 2017).

Quando se trata do dinamismo da relação social entre as pessoas e o conhecimento, este não pode estar sujeito e sob o controle de uma ferramenta simplesmente documental. Assim, pode-se assumir numa certa magnitude, que não se gerencia a criação do conhecimento, mas criam-se condições de capacitação para o conhecimento, que podem ser gerenciadas (VON KROGH et al., 2001). Tais condições podem ser traduzidas em práticas para a GC, podendo haver argumentos favoráveis ou desfavoráveis para sua execução, ou seja, facilitam ou dificultam a sua efetividade. Assim, "a troca de experiências bem-sucedidas pode contribuir para o estabelecimento de uma cultura organizacional voltada à inovação" (BESSI et al., 2017, p.324). Terra $(2001,2007)$ entende como necessário voltar esforços para fazer com que o conhecimento de uma organização esteja disponível para aqueles que dele necessitem, quando se faça necessário, onde se faça necessário e na forma como se faça necessário, com o objetivo de aumentar o desempenho humano e organizacional. Como salienta Burger et al.

Perspectivas em Gestão \& Conhecimento, João Pessoa, v. 10, n. 1, p. 39-53, jan./abr. 2020. 
(2018), o conhecimento deveria estar acessível a todos numa organização.

É nessa lógica defendida por Burger et al. (2018) que a GC é percebida como um processo resultante de um conjunto de habilidades e competências humanas dinamicamente envolvidas com o conhecimento, estando diretamente relacionada com a gestão de pessoas (GP). Quando o conhecimento é entendido como processo, o investimento nas pessoas proporcionará melhores resultados para a organização. É nesse sentido que Gonçalo e Borges (2010) falam que as práticas de GC estão diretamente relacionadas ao gerenciamento. Para Dalkir (2011) a GC é entendida como a administração dos ativos de conhecimento de dentro das organizações, proporcionando à organização saber o que ela sabe.

Diante desses conceitos, o ponto em comum desses autores em relação ao tema é a abordagem da GC, de suas dimensões que sugerem práticas ou ações atenuantes, que demonstram existir ou não a GC nas organizações. Assim, infere Dalkir (2005, p. 3), que a GC é:

Coordenação deliberada e sistemática de pessoas, tecnologias, processos e estrutura da empresa na busca da criação de valor através do recurso do conhecimento e inovação. Essa coordenação é realizada através da criação, compartilhamento e aplicação do conhecimento como por meio de alimentação de valiosas lições aprendidas e das melhores práticas dentro da memória corporativa, fomentando continuamente a aprendizagem organizacional.

A construção do conhecimento como um ciclo ( $\mathrm{CHOO}, 2006)$ confirma além dos conhecimentos tácito e explícito (NONAKA; TAKEUCHI, 1997), um terceiro conhecimento nas organizações, que é o conhecimento cultural, presente nas crenças, pressupostos e compromissos, gerando a atribuição de valor e significado aos novos conhecimentos, os quais preconizam amor, cuidado, confiança e compromisso que são base da criação do conhecimento (NONAKA; TOYAMA; BYOSIÈRE, 2001).

Consequentemente, o conhecimento existente nas pessoas e é a eficiência que determinará o sucesso da empresa, cujas ações poderão diferenciá-la de seus concorrentes. Assim, a criação do conhecimento leva à inovação contínua e, por sua vez, leva a vantagens competitivas, como exemplo o lançamento de um produto novo ou processo com melhores resultados, além da percepção das pessoas de que há um sentido de pertencimento.

Nonaka e Takeuchi (1997) estabeleceram um marco para a GC ao desenhar como a utilização do conhecimento tácito e explícito, utilizados consciente ou inconscientemente no dia a dia, e a combinação entre eles podem gerar quatro processos, que integrados formam o ciclo da criação do conhecimento, o modelo SECl: Socialização, Externalização, Combinação e Internalização. Acredita-se que ao sistematizar este ciclo, ações facilitadoras poderão emergir para implementar a GC, em suas sete dimensões (TERRA, 2007).

Para Terra (2007) a GC é um processo permanente que está associado a evolução organizacional. Assim, Terra $(2001,2007)$ desenha em seu estudo o modelo das sete dimensões, desenvolvido na primeira tese de doutorado defendida na área de GC no Brasil. Neste os desdobramentos das práticas gerenciais são divididos em sete diferentes dimensões ou práticas, as quais constituem-se em foco deste estudo para compreensão da GC, conforme é demonstrado no Quadro 1: 
Quadro 1 - As sete dimensões da GC na concepção de José Cláudio Cyrineu Terra

\begin{tabular}{|c|c|}
\hline $\begin{array}{l}\text { Dimensões } \\
\text { Práticas }\end{array}$ & Comentário \\
\hline $\begin{array}{l}\text { 1) Fatores } \\
\text { estratégicos e o } \\
\text { papel da alta } \\
\text { administração }\end{array}$ & $\begin{array}{l}\text { Destaca a importância da alta administração nos procedimentos de liderança, } \\
\text { sendo fundamental na demarcação de conhecimentos a serem explorados pela } \\
\text { empresa. Evidencia de forma transparente a estratégia empresarial, } \\
\text { estabelecimento de metas desafiadoras e inovação. }\end{array}$ \\
\hline $\begin{array}{lr}\text { 2) Sistemas de } \\
\text { informação } \\
\text { comunicação }\end{array}$ & $\begin{array}{l}\text { A GC associada a TI, relaciona-se a utilização dos sistemas de informação para } \\
\text { compartilhar informações e conhecimentos. Portanto somente a tecnologia } \\
\text { não está apta a administrar uma empresa e não é garantia de bons resultados. } \\
\text { O elemento humano é primordial, pois, são as pessoas que criam, } \\
\text { compreendem e usam a informação. A confiança estabelecida entre a } \\
\text { organização e os trabalhadores é relevante para o compartilhamento do } \\
\text { conhecimento. Os sistemas de informação são instrumento que qualificam e } \\
\text { armazenam o fluxo de conhecimento na organização. }\end{array}$ \\
\hline $\begin{array}{l}\text { 3) Cultura e } \\
\text { valores } \\
\text { organizacionais }\end{array}$ & $\begin{array}{l}\text { Normas e valores estabelecidos na empresa. Desenvolvimento de processos } \\
\text { criativos e de aprendizagem, conduta democrática, evitando o pré-julgamento } \\
\text { das ideias, aceitação da discussão de ideias "pífias, bobas" e indulgência com o } \\
\text { erro. Favorecer os ambientes de trabalho para a integração e comunicação das } \\
\text { pessoas. }\end{array}$ \\
\hline $\begin{array}{l}\text { 4) Estrutura } \\
\text { organizacional }\end{array}$ & $\begin{array}{l}\text { Rompimento com a burocracia, com enfoque maior nas pessoas e seu } \\
\text { conhecimento, sendo direcionadas para a criação e inovação. Trabalho em } \\
\text { equipe, alternância na liderança quanto as prioridades dos projetos, } \\
\text { minimização da hierarquia, e valorização da rede de aprendizados e memória } \\
\text { organizacional. }\end{array}$ \\
\hline $\begin{array}{l}\text { 5) Administração } \\
\text { de } \quad \text { Recursos } \\
\text { Humanos }\end{array}$ & $\begin{array}{l}\text { Recrutamento e seleção como função estratégica. Infere processo seletivo } \\
\text { mais detalhado, com várias fases, entrevistas, estudos de caso, dinâmicas } \\
\text { coletivas e de longa duração. Critérios de contratação e promoção claros, e } \\
\text { rigorosos, evitando o envolvimento da alta administração. Migração do } \\
\text { paradigma de treinamento para o paradigma do aprendizado, incluindo: } \\
\text { compartilhamento de ideias e conhecimentos, aprendizagem em equipe, } \\
\text { importância dada à intuição e conhecimento tácito e, avaliação dos resultados } \\
\text { por meio das melhorias no trabalho. Empresas que estimulam os } \\
\text { trabalhadores a terem carreiras envolvendo experiências diversificadas, } \\
\text { aumentam seu potencial de criatividade e ampliam as redes sociais internas } \\
\text { nas várias áreas e nos diversos campos de conhecimento da empresa. Para os } \\
\text { sistemas de recompensa, o autor enfatiza que não existe consonância em se } \\
\text { ressaltar o trabalho em equipe e cooperação e direcionar o sistema de } \\
\text { pagamento apenas para o desempenho individual, uma vez que além da } \\
\text { remuneração monetária, existem outras formas de reconhecer o esforço e } \\
\text { desempenho dos trabalhadores. }\end{array}$ \\
\hline $\begin{array}{l}\text { 6) Mensuração de } \\
\text { resultados }\end{array}$ & $\begin{array}{l}\text { Ressalta a importância da utilização de poucos indicadores, mas que avaliem as } \\
\text { diversas áreas simultaneamente, evidenciando relações sistêmicas. } \\
\text { Abordagem recente aos esforços para mensurar o capital intelectual e discorre } \\
\text { sobre suas fontes internas (capital de liderança, capital social, capital estrutural } \\
\text { e capital humano) e fontes externas (capital de rede - Network Capital). A } \\
\text { avaliação das áreas evidenciando as relações sistêmicas: financeiro/ contábil, } \\
\text { operacional, estratégico, e ativos intangíveis, baseados em conhecimento, que } \\
\text { ainda são difíceis de mensurar, e se os gestores com suas equipes estão } \\
\text { criando e gerando valor para a empresa. }\end{array}$ \\
\hline $\begin{array}{l}\text { 7) Oportunidade } \\
\text { de Aprendizado } \\
\text { com o ambiente }\end{array}$ & $\begin{array}{l}\text { Abordagem voltada ao aprendizado por meio da formação redes, clusters e } \\
\text { alianças empresariais, não se limitando apenas nas relações com os clientes, } \\
\text { mas ao aprendizado e redes com fornecedores. Abordagem ao benchmarking e } \\
\text { inteligência competitiva, para mensurar resultados com empresas do mesmo }\end{array}$ \\
\hline
\end{tabular}

Perspectivas em Gestão \& Conhecimento, João Pessoa, v. 10, n. 1, p. 39-53, jan./abr. 2020. 


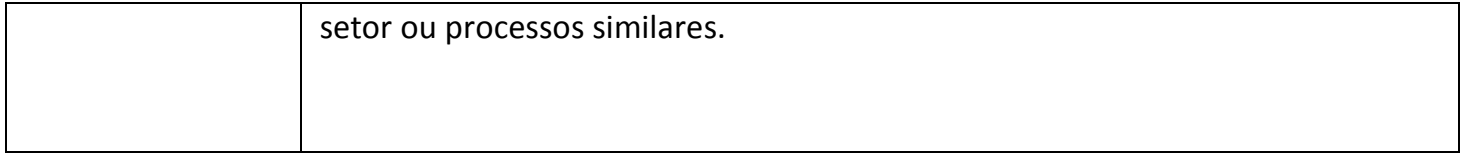

Fonte: adaptado de Terra (2007)

As dimensões expostas no Quadro 1 não devem ser vistas ou trabalhadas isoladamente, uma vez que dependem da análise de diversas variáveis, como feedbacks que dependem da maneabilidade, significância, oportunidade e constância, características descritas por Hartshorn (2008), bem como, também dependem da análise do ambiente econômico, social e político, da evolução tecnológica e da concepção sobre a natureza humana, e ainda, como estas se relacionam.

\section{PROCEDIMENTOS METODOLÓGICOS}

No que se refere aos procedimentos metodológicos desta pesquisa, o método adotado é o estudo de casos múltiplos (YIN, 2005), de natureza exploratória e descritiva (YIN, 2016), por permitir maior profundidade na pesquisa. A singularidade dos dados coletados por diferentes técnicas possibilita a comparação dos resultados, evidenciando múltiplas evidências que conferem maior robustez ao estudo. Quanto à abordagem do problema configura-se como uma pesquisa qualitativa (FLICK, 2009; YIN, 2016).

Constituem-se como campo de pesquisa três médias empresas industriais do ramo metalúrgico, cujos os nomes aqui utilizados são fictícios (Alfa, Beta e Gama), para preservação do sigilo. A escolha do setor metalúrgico se deve em razão da representatividade na atividade econômica industrial de diversas regiões do País, o que não é diferente na cidade pesquisada. E a escolha dessas três empresas industriais se deu por acessibilidade, após a definição do porte, e obviamente, o ramo.

Inicialmente trabalhou-se com um projeto piloto para alinhamento dos instrumentos de coleta, que após retificados, permitiu estender a pesquisa às demais empresas industriais, seguindo-se o protocolo de pesquisa. Os dados foram coletados por meio de técnicas diversificadas: entrevista semiestruturada, observação não participante e análise documental. A entrevista foi realizada junto a dezessete gestores, tendo como tempo médio de duração 50 minutos. Por sua vez, a observação não participante abrangeu todos os trabalhadores das empresas industriais, momentos em que notas de campo foram registradas. Por fim, a análise documental seguiu um padrão de registro de acordo com o objetivo da pesquisa.

Após a organização dos dados, esses foram triangulados e analisados de acordo com a análise de conteúdo (BARDIN, 2009), seguindo as três etapas proposta pela autora: leitura flutuante do material, organização do corpus de pesquisa de acordo com as categorias previamente definidas e, por fim, as análises inferenciais conforme o referencial teórico. Como categorias analíticas foram trabalhadas as sete dimensões da GC propostas por Terra (2007): fatores estratégicos e o papel da alta administração, sistemas de informação e comunicação, cultura e valores organizacionais, estrutura organizacional, administração de Recursos Humanos (ARH), mensuração de resultados e oportunidade de aprendizado com o meio ambiente. Assim foi possível analisar as práticas no campo de estudo, no que se refere aos facilitadores e as barreiras para implementação da GC.

\section{APRESENTAÇÃO E DISCUSSÃO DOS RESULTADOS}

As sete dimensões da GC estudadas por Terra $(2001,2007)$ são desenvolvidas e percebidas na rotina dos três casos estudados, embora algumas evidenciadas na fase inicial de implementação e não reconhecidas ainda como práticas da GC. Este estudo demonstra que a

Perspectivas em Gestão \& Conhecimento, João Pessoa, v. 10, n. 1, p. 39-53, jan./abr. 2020. 
GC pode ser um caminho factível e mensurável, ao elencar algumas ações facilitadoras que a tornam viável, entretanto, não se pode negar as práticas limitadoras que dificultam a GC.

Tais dimensões da GC constituem-se em práticas observadas no contexto empírico, onde se identifica barreiras e facilitadores. As referidas práticas necessitam ser compreendidas e aplicadas de fato para ocorrer a GC, daí a importância de se identificar os facilitadores e as barreiras. É nessa lógica que as evidências empíricas são analisadas aqui.

Um único indicador ao ser mensurado, avaliado e controlado, produzirá resultados satisfatórios para o cumprimento de várias metas. Exemplifica-se com a ação facilitadora de mensurar a quantidade de projetos e patentes, que pode levar a uma mobilização direcionadora para que mecanismos como metas e indicadores sejam acionados. Um outro facilitador da GC são os feedbacks, caracterizado por Hartshorn (2008) como eficaz ao cumprir algumas características descritas como maneabilidade, significância, oportunidade e constância. A possibilidade de todos serem ouvidos facilita, sobremaneira, o compartilhamento e a internalização de conhecimentos.

Destaca-se outros elementos facilitadores importantes evidenciados nesta pesquisa empírica: profissionalização, valorização dos trabalhadores e oportunização de mais treinamentos, os quais necessitam ser apoiados pela área de GP, sendo esta aliada imprescindível para a implementação da GC. Dessa forma, segue-se o que é defendido por Burger et al. (2018). Assim, quando ocorre o trabalho em conjunto (alta direção e GP), os trabalhadores da indústria percebem claramente esse objetivo de aprendizado e troca de conhecimentos.

Para que as demais dimensões propiciem também ações coniventes ao desencadeamento de mais ações facilitadoras, dependem, além da estrutura organizacional, da vontade das pessoas. Isso pode ser exemplificado com a fala do entrevistado E4: "para dificultar a GC uma das coisas é o ser humano, tem dificuldade de ter alguém que queira aprender. Ensina motivando eles e demonstrando aquilo que eles têm que fazer". Com base em Terra (2007) pode-se inferir que a estrutura organizacional é uma dimensão para facilitar a GC, que mesmo não tendo relação direta com o desempenho da empresa, influencia positivamente esse, ou seja, a estrutura organizacional exerce alta relação, resultando maior excelência operacional, realização não financeira e até a realização financeira, o que é defendido por Wu e Chen (2014).

Uma ação que complementaria a dimensão estrutura organizacional, seria criar artefatos, como ambientes propícios e situações simuladas, para fomentar a vontade de aprender, que nada mais é do que iniciativas que corroboram com a fala de autores como Gonçalo e Borges (2010), envolvendo a GC compreendida como um processo decorrente do desenvolvimento de pessoas, melhoria nas suas habilidades e competências, adquiridas com o compartilhamento, externalização e internalização dos conhecimentos.

Por outro lado, alguns limitadores dificultam a implementação das práticas da GC, o que também está relacionado à forma de gestão das equipes, "gerência" da emergência do novo conhecimento (NONAKA et al., 2002). A ausência da gestão estratégica, a falta de participação efetiva da alta administração, não conhecer as principais práticas da GC e pensar que gerir o conhecimento gera custo, constituem-se em barreiras para as práticas da GC, impedindo o desenvolvimento das demais dimensões, bem como a ausência do controle de indicadores. Também a falta de cultura do aprendizado e da inovação pode ser uma barreira para a indústria inovar e desenvolver práticas de GC, como pontuam e Bessi et al. (2017) e Burger et al. (2018). Por fim, cabe salientar o principal limitador: indiferença ou ausência da gestão de $\mathrm{RH}$, que pode levar os próprios trabalhadores perderem o entusiasmo pelos resultados, uma vez que percebem que muito mais poderia ser feito para incentivá-los no alcance dos resultados. Os relatos que seguem demonstram claramente a falta que faz a área que trata das pessoas: "se tivesse um setor para reunir os funcionários para conversar sobre as 
ideias e o que podemos fazer para melhorar ainda mais, a gente se sentiria mais motivado, porque aqui o RH somente faz os pagamentos e alguns treinamentos" (E16) e "não percebo que tem RH aqui na empresa, eu acho que eles só trabalham com papéis, só isso. Gente vindo aqui, olhando pela gente, pensando no que precisamos, até o que precisamos aprender mais... não tem, não percebo" (E11).

No Quadro 2, na busca de uma síntese, apresenta-se um demonstrativo dos facilitadores e barreiras para a GC nas três indústrias pesquisadas:

Quadro 2 -Facilitadores e barreiras para a GC

\begin{tabular}{|c|c|c|c|}
\hline Elementos & Indústria Alfa & Indústria Beta & Indústria Gama \\
\hline Facilitadores & $\begin{array}{l}\text { Programas internos (sua } \\
\text { ideia vale prêmios). } \\
\text { Apoio da área de GP, nas } \\
\text { práticas da GC. } \\
\text { Indicadores mensuráveis, } \\
\text { por setor, e comunicação } \\
\text { efetiva dos mesmos. }\end{array}$ & $\begin{array}{l}\text { Trabalhadores jovens, } \\
\text { formação superior, novas } \\
\text { ideias. } \\
\text { Uso de espaços abertos, } \\
\text { sala do café e salas de } \\
\text { reunião. } \\
\text { Intenção para conhecer } \\
\text { melhor as dimensões da GC } \\
\text { e desenvolver um método } \\
\text { próprio de tabulação de } \\
\text { indicadores para avaliar os } \\
\text { resultados em GC. }\end{array}$ & $\begin{array}{l}\text { Feedback individual. } \\
\text { Habilidade de calcular } \\
\text { riscos. }\end{array}$ \\
\hline Barreiras & $\begin{array}{l}\text { Políticas e normas de } \\
\text { cargos e salários, PPLR, } \\
\text { esclarecimento de } \\
\text { benefícios e políticas de RH } \\
\text { ainda insipientes. } \\
\text { O trabalhador não percebe } \\
\text { o aprendizado e não } \\
\text { colabora. } \\
\text { Falta conhecimento das } \\
\text { práticas de GC e ações. }\end{array}$ & 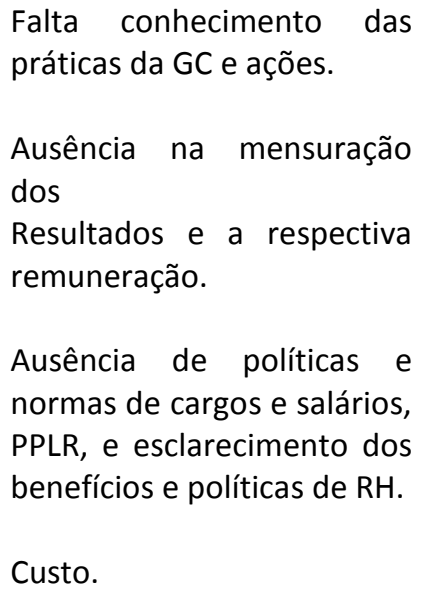 & $\begin{array}{l}\text { Ausência da mensuração } \\
\text { dos resultados e } \\
\text { respectiva remuneração. } \\
\text { Falta conhecimento das } \\
\text { práticas da GC e ações. } \\
\text { Ausência de políticas e } \\
\text { normas de cargos e } \\
\text { salários, PPLR, } \\
\text { esclarecimento de } \\
\text { benefícios e políticas de } \\
\text { RH. }\end{array}$ \\
\hline
\end{tabular}

Fonte: Elaborado pelas autoras (2018)

Na sequência da pesquisa também foi possível definir com maior precisão as práticas facilitadoras e/ou limitadoras em cada dimensão de Terra (2007). Mesmo com a constatação de práticas que podem acelerar a GC ou retardar a implementação das sete práticas, pode-se inferir que uma ou outra dimensão pode atuar independentemente, e deixa indícios de que a GC pode gerar uma percepção atribuída aos trabalhadores.

Todavia, as evidencias empíricas apontam que há uma vontade premente dos responsáveis pela gestão e das próprias equipes, em trabalhar para que os indicadores, dimensões e suas práticas se tornem rotina, comprovado pela seguinte fala: "Acredito que a GC pode ser um indicador do desempenho organizacional, porque com mais informações você tem mais conhecimento e consegue crescer. Agora como tabular a gente vai ter que aprender" (E4).

Perspectivas em Gestão \& Conhecimento, João Pessoa, v. 10, n. 1, p. 39-53, jan./abr. 2020. 
Tais práticas facilitadoras, podem desencadear resultados significativos para agregar e integrar o desempenho organizacional como excelência operacional, intimidade com o cliente, liderança de produto e satisfação financeira, como afirmam Wu e Chen (2014), influenciado pelas ações atuantes e constantes das práticas da GC no dia a dia. Portanto, entende-se que ao serem aplicadas todas as dimensões da GC, e como infere Juran (1992), dizer em números, em valores ou quantidades, ou periodicidade, uma prática poderá facilitar a execução da outra e, assim, consequentemente compreender a demanda necessária da atuação das dimensões e respectivas ações para acelerar os resultados em desempenho organizacional. Nesse sentido, segue fala comprobatória: "O setor de faturamento faz a mensuração, tem a meta e tem que atingir no mínimo $60 \%$ da meta. No meu setor, todos estão sendo feitos. 0 meu setor faz a quantidade de vendas e valor de vendas" (E13).

Com base nas evidências empíricas também foi possível perceber a importância da cultura, aprendizagem e a tecnologia da informação (TI) como moderadores da GC, uma vez que ao ser instaurada uma cultura do aprendizado e do controle dos indicadores com o auxílio da TI, facilitariam sobremaneira a GC. Tais questões são salientadas por Terra (2007) e os dados empíricos comprovam que tais limitadores e facilitadores fazem parte da rotina das empresas industriais pesquisadas, porém ainda não são reconhecidas como caminhos para a GC, uma vez que as sete dimensões não são conhecidas pela gestão destas empresas.

Na sequência, no Quadro 3, em cada uma das sete dimensões de Terra (2007) são apresentadas algumas ações que são facilitadoras ou barreiras para a GC nas empresas industriais pesquisadas:

Quadro 3 - Facilitadores e barreiras das sete dimensões de Terra (2007)

\begin{tabular}{|c|c|c|}
\hline $\begin{array}{l}\text { Práticas das dimensões da } \\
\text { GC (TERRA, 2007) }\end{array}$ & Facilitadores & Barreiras \\
\hline $\begin{array}{l}\text { 1) Fatores estratégicos e o } \\
\text { papel da alta administração }\end{array}$ & $\begin{array}{l}\text { Disseminação de macro } \\
\text { estratégias para todos os } \\
\text { trabalhadores. Exposição em } \\
\text { murais das metas desafiadoras. } \\
\text { Reuniões periódicas. }\end{array}$ & $\begin{array}{l}\text { Dificuldade em tomar decisões e } \\
\text { definir macro estratégias. }\end{array}$ \\
\hline $\begin{array}{l}\text { 2) Sistemas de informação e } \\
\text { comunicação }\end{array}$ & $\begin{array}{l}\text { Um canal direto de troca de } \\
\text { informação entre gestão, } \\
\text { estratégico com o operacional. }\end{array}$ & $\begin{array}{l}\text { Resguardo de informações por } \\
\text { parte dos trabalhadores como } \\
\text { meio de manter maior } \\
\text { competitividade/poder. } \\
\text { Dificuldades na didática da } \\
\text { comunicação para ser padrão, } \\
\text { desde o estratégico até o } \\
\text { operacional. }\end{array}$ \\
\hline $\begin{array}{l}\text { 3) Cultura e valores } \\
\text { organizacionais }\end{array}$ & $\begin{array}{l}\text { Cultura do conhecimento, da } \\
\text { qualidade e da inovação. }\end{array}$ & $\begin{array}{l}\text { Falta de autonomia, de } \\
\text { integração, de valorização do } \\
\text { tempo e do aprendizado } \\
\text { contínuo. }\end{array}$ \\
\hline $\begin{array}{l}\text { 4) Estrutura } \\
\text { organizacional }\end{array}$ & $\begin{array}{l}\text { O funcionamento e processos de } \\
\text { trabalho, orientados a projetos. } \\
\text { Há sentimento de confiança } \\
\text { entre os trabalhadores. } \\
\text { Cronograma de reuniões e } \\
\text { espaços apropriados com } \\
\text { utilização de ferramentas para } \\
\text { avaliação, medição e exposição } \\
\text { de resultados alcançados. }\end{array}$ & Nada constatado. \\
\hline
\end{tabular}

Perspectivas em Gestão \& Conhecimento, João Pessoa, v. 10, n. 1, p. 39-53, jan./abr. 2020. 


\begin{tabular}{|c|c|c|}
\hline $\begin{array}{l}\text { 5) Administração } \\
\text { Recursos Humanos }\end{array}$ & $\begin{array}{l}\text { Trabalho interativo e } \\
\text { desenvolvimento de políticas } \\
\text { para a mensuração das metas e } \\
\text { remuneração dos indicadores. }\end{array}$ & $\begin{array}{l}\text { Ausência de políticas claras na } \\
\text { mensuração dos resultados e } \\
\text { respectiva remuneração. } \\
\text { Sentimento da necessidade de } \\
\text { maior valorização dos resultados } \\
\text { não financeiros. } \\
\text { Falta de proximidade com } \\
\text { demais setores para definir } \\
\text { políticas próprias do setor. }\end{array}$ \\
\hline $\begin{array}{l}\text { 6) Mensuração } \\
\text { Resultados }\end{array}$ & $\begin{array}{l}\text { Premiação para as equipes de } \\
\text { trabalho pelo atingimento das } \\
\text { metas. }\end{array}$ & $\begin{array}{l}\text { Inexistência de um plano de } \\
\text { remuneração variável com } \\
\text { abrangência total. } \\
\text { Falta de conhecimento em como } \\
\text { mensurar resultados relativos a } \\
\text { gestão de pessoas e GC. }\end{array}$ \\
\hline $\begin{array}{l}\text { 7) Oportunidade de } \\
\text { aprendizado com o ambiente } \\
\text { interno e externo }\end{array}$ & $\begin{array}{l}\text { Implementação de programas } \\
\text { para percepção do aprendizado. } \\
\text { Contratação de consultoria para } \\
\text { auxiliar nas dinâmicas. } \\
\text { Participação em feiras, mostras e } \\
\text { eventos. }\end{array}$ & $\begin{array}{l}\text { O trabalhador nem sempre } \\
\text { percebe o aprendizado e não } \\
\text { colabora. O trabalhador acredita } \\
\text { que já sabe o suficiente. Medo } \\
\text { da mudança e do novo, dificulta } \\
\text { o aprendizado contínuo. }\end{array}$ \\
\hline
\end{tabular}

Fonte: Elaborado pelas autoras (2018)

O Quadro 3 demonstra que após descrever os espaços organizacionais das empresas industriais selecionadas para o estudo, foi possível identificar algumas práticas de GC destacadas também por Terra (2007), tais como: dispor de layouts conducentes às trocas informais de informações (uso de espaços abertos, sala do café e salas de reunião), uso constante de equipes multidisciplinares e formais que se sobrepõem à estrutura formal tradicional e hierárquica, delegação de autonomia e dedicação total a projetos inovadores. Seguem falas comprobatórias: "Reconhece-se que tempo é um recurso importante para o processo de inovação, o tempo é fundamental" (E15) e "Cada um é de uma área, isso é ótimo. Eu posso não entender de algo, mas tenho com quem trocar ideias e isso acontece aqui naturalmente".

Também ficou evidenciada uma cultura de reconhecimento, da necessidade de atuação dos engenheiros, do conhecimento técnico, o que é também fica comprovado na fala de um gestor e proprietário de uma empresa industrial, quando infere: "Há engenheiros do conhecimento que vão para o exterior como EUA, participar de feiras e trazer novidades" (E14). Portanto, o fato da liderança admitir que pessoas talentosas de sua empresa, deslocamse para países que são referência na inovação, para buscar conhecimento em feiras e eventos e trazer as novidades, e ainda, chamá-los de engenheiros do conhecimento, corrobora com a fala de autores como Wiig (2004), em relação a GC.

Porém, não ocorre o mesmo com a dimensão ARH (TERRA, 2007), sendo que na pesquisa empírica constatou a necessidade de maior atenção para essa dimensão, a qual interfere no conhecimento das pessoas sobre GC. Talvez somente após um olhar mais atento aos seus trabalhadores é que as organizações consigam instaurar e gerir o seu conhecimento para fortalecer a relação com o desempenho organizacional. A proximidade no relacionamento entre os trabalhadores das empresas e seus gestores, precede de uma maior valorização da área de $\mathrm{RH}$, que ao trabalhar com números e mostrar resultados financeiros e não financeiros, possa ter maior credibilidade.

Pesquisadores empreendem para colaborar com abordagens mais eficazes da medição do desempenho, tanto as medidas de desempenho financeiro como as não financeiro (HO;

Perspectivas em Gestão \& Conhecimento, João Pessoa, v. 10, n. 1, p. 39-53, jan./abr. 2020. 
AHMAD; RAMAYAH, 2016; SIMON et al., 2015). A área de RH também deve apresentar medidas de desempenho, tanto financeiras como não financeiras. A cultura da aprendizagem $e$ a GC servem como medidas. Portanto, a cultura da aprendizagem e do conhecimento, implementada pela GP, pode ser um grande facilitador da GC, do querer aprender mais numa espiral contínua, ou num movimento orbital, quando não cíclico.

No que se refere aos indicadores com o intuito de mensurar a mobilização dos setores para seguir o planejamento estratégico, leva em conta os indicadores que foram implementados para esse fim, conforme menciona a coordenadora de GP: "A maioria das áreas tem indicadores, como treinamento, absenteísmo, turnover, controle de custos com pessoal, de orçamento, assim temos vários, quando você vier fazer a observação posso compartilhar contigo" (E6). O que de fato foi evidenciado pelos documentos apresentados, como as listas de presença em treinamentos e avaliação de eficácia, planilhas de controle de indicadores e murais com resultados de indicadores expostos nos corredores e nas paredes dos setores. Von Krogh (2001) e Bessi et al. (2017) salientam a necessidade de tais controles.

Muito provavelmente agora, em razão da pesquisa realizada, as três empresas industriais estejam mais cientes quanto as práticas e dimensões da GC, percebendo se elas são ou não atuantes nas práticas do seu dia-a-dia, bem como se estão presentes. Assim, mais conscientes, podem vir a buscar a GC. A continuidade do ciclo da criação do conhecimento, como a combinação e a internalização ainda primam por mecanismos para transformar conhecimentos tácitos em explícitos, concluindo assim o ciclo, tanto da criação do conhecimento como para se completar também a sistemática da GC em cada empresa industrial.

Analisando as evidências empíricas dos três casos estudados, observa-se que a cultura da aprendizagem pode ser inserida e melhor trabalhada, especialmente pela dimensão administração de $\mathrm{RH}$, preparando e capacitando os gestores para ações gerenciais de incentivo ao compartilhamento de ideias, para proliferar a cultura da aprendizagem e também inovação, bem no sentido referido por Bessi et al. (2017), inclusive aliada a TI, o que pode facilitar sobremaneira a efetividade da GC.

Implementar concretamente algumas práticas facilitadoras da GP concomitante a GC para renovar o setor de $\mathrm{RH}$ e, consequentemente desempenhar a quinta dimensão de Terra (2007), administração de RH, a qual ainda necessita ser concretizada no sentido de existir de fato e ser seguida por todos. Nesse sentido, também trabalhar com indicadores, ou seja, se não tem indicadores, criar; se há indicadores, mensurar, controlar, reavaliar, atingir, remunerar e comunicar. Isso pode fazer parte das políticas do RH das empresas industriais, o que contribuiria eminentemente para a GC. Assim, constata-se visivelmente que a dimensão ARH necessita ser melhor reconhecida e trabalhada nas médias empresas industriais como ponto central para seu desempenho, desenvolvimento e expansão.

Ao realizar à implementação das dimensões da GC, quanto mais ações e mais práticas, propiciadas pela GP, maiores serão os resultados agregados ao desempenho organizacional, como excelência operacional, intimidade com o cliente, liderança de produto e realização financeira (WU; CHEN, 2014), corroborando com Wiig (2004), o qual infere que há uma perspectiva no papel dos ativos fatores, direcionadores, habilitadores, facilitadores e mecanismos trabalhados nas mesmas perspectivas pelo $\mathrm{RH}$, que ao se associarem por meio de ações motivadas pela GP, possibilitam a visualização dos meios que facilitam as práticas das GC, consequentemente propiciando maiores desempenhos para a empresa, e para as pessoas.

Assim, as realizações como resultados agregados e medidas de desempenho e ganhos não financeiros (HO; AHMAD; RAMAYAH, 2016; SIMON et al., 2015), merecem um destaque para instigar a vontade das pessoas em querer aprender, sem o intuito de ganhar mais financeiramente, contudo de agregar ganhos como novas competências ou valores pessoais. Dessa forma, compreendendo o seu importante papel como ser humano detentor de 
conhecimentos, que podem gerar conhecimentos ainda mais significativos em prol de uma coletividade, como uma organização.

Para que todos os trabalhadores de uma organização se envolvam no processo da GC, há que se esclarecer o conceito da GC e sua afinidade com a área de GP, elucidando que há possibilidade de ambas complementarem-se. Essa evidência poderá ser concretizada, quando a GC for amparada por indicadores, o que possibilitará um melhor entendimento e disseminação dessa. Assim, o resultado gerado para a GC no desempenho organizacional, transparecido em números, poderá ser um conceito melhor compreendido pelos trabalhadores das empresas industriais. Dessa maneira, como referem Terra $(2001 ; 2007)$ e Ribeiro et al. (2017), é válido o esforço para a implementação da GC, dado o aumento tanto do desempenho humano como o organizacional.

\section{CONSIDERAÇÕES FINAIS}

Este estudo permitiu verificar que a criação do conhecimento e a GC estão imbricadas e, como uma espiral contínua e evolutiva, geram desempenho pessoal e organizacional. Porém, há que se relacionar a GC intimamente com a área de GP, principalmente nas macros estratégias da alta administração e nos sistemas de informação e comunicação, bem como na mensuração dos resultados. Não se nega as dificuldades envolvidas para a GC no meio organizacional, o que não é diferente nas médias empresas industriais aqui pesquisadas. Então, por mais que as barreiras são inegáveis, ficaram evidentes os facilitadores que contribuem para a implementação da GC. É nessa lógica que este artigo traz a sua contribuição, demonstrando claramente a existência de facilitadores e de barreiras na GC, as quais impactam diretamente no desempenho organizacional. Portanto, cada organização deve planejar o seu "caminho" para a GC, visando facilitar a sua implementação e a obtenção de resultados positivos tanto para ela como para os seus trabalhadores,

Portanto, em termos de contribuição prática e mais específica, com o resultado desta pesquisa empírica acredita-se que as referidas práticas da GC podem ser facilitadas ao incrementar a quinta dimensão, a ARH. O efetivo trabalho da ARH significaria um reflexo bastante positivo, atribuindo avanços consideráveis para a implementação das demais práticas de GC nas organizações, bem no sentido defendido por Terra (2007). Fica evidenciado que muitos fatores afetam a implementação de GC, os quais podem influenciar a eficácia, a eficiência e o desempenho geral do sistema de GC e da organização como um todo. Entretanto, não se pode negar que existem "caminhos" para facilitar a GC.

Para a área acadêmica as implicações teóricas deste artigo são pertinentes ao trabalhar especificamente com facilitadores e barreiras a GC, fomentando mais estudos, sobretudo empíricos. Nessa lógica, como sugestão específica de pesquisa, entende-se que uma pesquisa quantitativa poderia ser realizada junto com todos os trabalhadores das empresas industriais pesquisadas, também se entende como pertinente que sejam realizados estudos posteriores nos quais os trabalhadores sem cargos gerenciais sejam ouvidos. Como sugestão mais ampla, acredita-se que devam ser realizadas pesquisas em outros segmentos de negócios, com abordagem tanto qualitativa como quantitativa, a fim de difundir o conhecimento das práticas da GC. Ainda como sugestão de pesquisas futuras, destaca-se a realização de mais estudos empíricos sobre a relação e impactos dos limitadores e facilitadores da GC para o desempenho organizacional e desempenho pessoal dos trabalhadores. Por fim, sugere-se então a aplicação do modelo das sete dimensões sugerido por Terra (2007), tanto para avançar nos estudos sobre o referido tema, quanto para sua melhor compreensão e implementação.

Chegando ao final desta pesquisa poder-se afirmar que a ausência de práticas e ações organizacionais colaborativas voltadas para a interação e troca de conhecimentos, limitam a

Perspectivas em Gestão \& Conhecimento, João Pessoa, v. 10, n. 1, p. 39-53, jan./abr. 2020. 
implementação das práticas da GC. Por outro lado, a existência de práticas organizacionais facilitadoras é propulsora da GC, melhorando o desempenho organizacional. Tais práticas dependem muito das pessoas e, principalmente, da alta direção, tornando-se um desafio para as lideranças.

Por fim, espera-se que os resultados apresentados nesse artigo colaborem para com a disseminação e conscientização da importância da GC nas organizações, incluindo as de menor porte, bem como com o crescimento das pesquisas sobre o tema, principalmente no Brasil. Conclui-se que não são as barreiras ou os elementos limitadores que devem imperar na implementação da GC na prática, ou mesmo nas pesquisas. Nessa lógica fica fácil responder ao questionamento do título esse artigo: facilitar ou dificultar?

\section{REFERÊNCIAS}

BARDIN, L. Análise de Conteúdo. Lisboa: Edições 70, LDA, 2009.

BESSI, V. G; PENEDO, K. S; BEZ, M. R.; SCHREIBER, D. Práticas de gestão do conhecimento em empresas do vale do Rio dos Sinos/RS. Revista Gestão e Planejamento, v. 18, p. 311-329, jan./dez. 2017. DOI: 10.21714/2178-8030gep.v18.4533

BURGER, F.; KRAEMER, R.; DANDOLINI, G. A.; SOUZA, J. A.; SÁ FREIRE, P. Barreiras, elementos dificultadores e fatores críticos na implementação da gestão do conhecimento: Uma revisão da literatura. Perspectivas em Gestão \& Conhecimento, v. 8, n. 2, p. 43-61, mai./ago. 2018. DOI: http://dx.doi.org/10.21714/2236-417X2018v8n2p43

CENTENARO, A.; BONEMBERGER, A. M. O.; LAIMER, C. G. Gestão do conhecimento e vantagem competitiva: estudo no setor metal mecânico. Revista de Ciências da Administração, v. 18, n. 44, p. 38-51, 2016.

CHEN, J. S.; TSOU, H. T. HUANG, A. Y. H. Antecedentes da inovação na prestação de serviços e impacto no desempenho da empresa. Diário de Service Research, v. 12, p. 36-55, 2009.

DALKIR, K. Knowledge management in theory and practice. Burlington: Elsevier, 2005.

FERNANDES, P. F; MENDIETA, A. C; SILVA, M. A. B. Fatores Facilitadores e Inibidores às Práticas de Gestão do Conhecimento em uma Grande Empresa Brasileira do Setor Industrial. Gestão \& Planejamento, Salvador, v.16, n. 2, p. 222-239, maio/ago, 2015.

FLICK, U. Introdução à pesquisa qualitativa. 3. ed. São Paulo: Artmed, 2009.

GONÇALO, C. R.; BORGES, M. L. A Gestão do Conhecimento Organizacional. In: BITENCOURT e colaboradores. Gestão Contemporânea de Pessoas: novas práticas, conceitos tradicionais. 2.ed. Porto Alegre, Bookman, 2010.

HARTSHORN, K. J. The effects of manageable corrective feedback on ESL writing accuracy. Brigham Young University, 2008. 
HO, T. C.; AHMAD, N. H.; RAMAYAH, T. Capacidades competitivas e desempenho de negócios entre PMEs de manufatura: evidências de uma economia emergente, Malásia. Jornal da ÁsiaPacifc Business, v. 17, p. 37-58, 2016.

JURAN, J. M. A qualidade desde o Projeto: Os novos passos para o planejamento da qualidade em produtos e serviços. São Paulo: Pioneira., 1992.

KROGH, G. V; ICHIJO, K.; NONAKA, I. Facilitando a criação do conhecimento: reinventando a empresa com o poder da inovação contínua. Rio de Janeiro: Campus, 2001.

NONAKA, I.; TOYAMA, R. E.; KONNO, N. SECI, ba and leadership: a unified model of dynamic knowledge creation. Managing knowledge an essential reader. London: Sage Publications, 2002.

POPADIUK, S. Gestão do conhecimento de reclamações de Clientes em Call Centers. Revista de Administração Mackenzie, v. 10, n. 2, art. 126, p. 135-16, 2009.

RAMOS, E. N. P.; HELAL, D. H. A prática da gestão do conhecimento em uma empresa familiar do ramo varejista em Minas Gerais (MG): um estudo de caso. JISTEM - Journal of Information Systems and Technology Management, v.7, n. 2, p. 433-452, 2010.

RIBEIRO, J. S. A. N.; CALIJORNE, M. A. S.; JURZA, P. H.; ZIVIANI, F.; NEVES, J. T. R. Gestão do conhecimento e desempenho organizacional: integração dinâmica entre competências e recursos. Perspectivas em Gestão \& Conhecimento, v. 7, n. 1, p. 4-17, 2017.

SIMON, A.; BARTLE, C.; STOCKPORT, G.; SMITH, B.; KLOBAS, J. E.; SOHAL, A. O negócio pontos de vista dos líderes sobre a importância das capacidades dinâmicas para o sucesso financeiro e desempenho comercial não-financeiro. Internacional Jornal de Produtividade e desempenho Managment, v. 64, p. 908-931, 2015.

SORDI, V. F.; CUNHA, C. J. C. A.; NAKAYAMA, M. K. Criação de conhecimento nas organizações: epistemologia, tipologia, facilitadores e barreiras. Perspectivas em Gestão \& Conhecimento, João Pessoa, v. 7, n. 2, p. 160-174, jul./dez. 2017.

TEIXEIRA, E. K.; OLIVEIRA, M. Métricas de gestão do conhecimento: análise em artigos publicados em periódicos científicos de 2001 a 2011. Revista ADM.MADE, v. 16, p.110-128, 2012.

TERRA, J. C. C. Gestão do conhecimento: o grande desafio organizacional. São Paulo: Negócio, 2001.

TERRA, J. C. C. Gestão do conhecimento: sete dimensões e 100 práticas gerenciais. São Paulo: Terra Fórum Consultores, 2007.

WIIG, K. M. People focused knowledge management: how effective decision making leads to corporate success. Elsevier, 2004.

WU, I. L.; CHEN, J. L. Knowledge management driven firm performance: the roles of business process capabilities and organizational learning. Journal of Knowledge Management, v.18, p. 114-1164, 2014.

Perspectivas em Gestão \& Conhecimento, João Pessoa, v. 10, n. 1, p. 39-53, jan./abr. 2020. 
YIN, R. K. Estudo de caso: planejamento e métodos. 3. ed. Porto Alegre: Bookman, 2005.

YIN, R. K. Qualitative Research from Start to Finish. Second Edition. New York: The Guilford Press, 2016. 